\title{
International Federations and National Governing Bodies: The Historical Development of Institutional Policies in Response to Challenging Issues in Sport
}

\author{
Jörg Krieger Lindsay Parks Pieper \\ Aarhus University University of Lynchburg \\ Ian Ritchie \\ Brock University
}

Historical accounts on the institutions that have shaped the history of sport (and sport history) have increasingly emerged in recent years. ${ }^{1}$ The main body of academic literature within the historiography of sport focuses on the International Olympic Committee (IOC). Despite the IOC's significance, international highperformance sport is also shaped by people and policies from outside the Olympic Movement. International Federations (IFs), National Federations, and other nongovernmental bodies are powerful stakeholders in the international sport system.

The IOC first acknowledged the important role of IFs in the 1910s. During the 1914 Olympic Congress, IOC President Pierre de Coubertin hesitantly accepted that the IFs would be the main bodies to determine amateur rules for their respective sports. ${ }^{2}$ The IOC subsequently shifted eligibility issues to the federations; however, questions about the scope of IFs' authority continued as the IFs believed their oversight also extended into determining the technical aspects of their sports. Fearful of a reduction in the size of the Olympic program, the French cycling administrator and journalist Paul Rousseau united all IFs under the "Permanent Bureau of International Sport Federation" in 1921, a forerunner to organizations such as SportAccord, the Association of Summer Olympic International Federations, and the Association of International Olympic Winter Sports Federations. The Permanent Bureau arranged meetings between the IOC and IFs to facilitate dialogue and express federation needs. ${ }^{3}$ Yet the IOC and IFs continued to dispute the balance of power. During the 1925 and 1930 Olympic Congresses, IOC and IF members debated responsibilities with federations ultimately assuming

Krieger is with the Department of Public Health, Aarhus University, Aarhus, Denmark. Pieper is with the University of Lynchburg, Lynchburg, VA, USA. Ritchie is with Brock University, St. Catharines, Ontario, Canada. Address author correspondence to Jörg Krieger at krieger@ph.au.dk. 
authority over the technical aspects of their individual sports. The arrangement established during this time provided IFs authority over sports but maintained their close connection to the IOC.

International Federations today are not-for-profit associations that govern an Olympic or non-Olympic sport on the international level. ${ }^{4}$ They are generally considered among the most important stakeholders of the Olympic system, together with the IOC itself, the National Olympic Committees, and the Organizing Committees of Olympic Games. ${ }^{5}$ The rights and obligations of each federation are defined in the Olympic Charter, which awards the IF the exclusive right to govern the specific sport. For example, the International Swimming Federation (FINA) oversees water sports, including artistic swimming, diving, high diving, open water swimming, swimming, and water polo.

Despite the academic and public focus on the IOC and the Olympics, all IFs host separate championship forums that generate tremendous profits. Although smaller IFs with little popularity outside the Olympic Games depend heavily on the television income of the Olympic Movement - which renders them more dependent on the wishes of the IOC-others have an independent economic impact on the sporting industry (and beyond). This grants them independence from Olympic governors. Perhaps as the most notable example, the Fédération Internationale de Football Association (FIFA), the international governing body for the sport of football, opted to install its own world championships in 1930. The IOC's strict interpretation of amateurism as a requirement for Olympic participation convinced FIFA to host a separate championship tournament with less stringent eligibility rules. ${ }^{6}$ The decision paved the way for the financial success of the FIFA World Cup; according to FIFA financial documents, the 2018 FIFA World Cup generated $\$ 6.1$ billion in revenue. ${ }^{7}$ FIFA's World Cup profits also allowed for professionalization in football outside of the IOC's control.

Similarly, the International Lawn Tennis Federation's (ILTA) dissatisfaction with the organization of the tennis events at the Olympic Games and its desire to enforce a more lenient definition of amateurism led the federation to leave the Olympic Movement ahead of the 1928 Olympic Games. ${ }^{8}$ Indeed, tennis did not return to the official Olympic program until sixty years later, by which point it had developed into a fully professionalized sport. In both cases, FIFA and the ILTA considered the Olympic Games unnecessary for their own success. The two federations regarded its championships as more prestigious and lucrative than the Olympic Games. ${ }^{9}$

In addition to economic influence, IFs also create policies that affect athletes, coaches, and officials. In reacting to perceived problems in their specific sports, international federations often act before the IOC, consequently influencing the ways in which Olympic governors eventually respond. For example, when the International Association of Athletics Federations (IAAF; since 2019 called World Athletics) believed male imposters were competing in women's track and field, it introduced sex testing. In 1966, the IAAF required all female athletes undergo a visual inspection prior to participation, before switching to a chromosome test the following year. The IOC followed the IAAF's example and required compulsory sex testing in $1968 .{ }^{10}$ Likewise, the IAAF was the first international sport organization to provide a definition for "doping" in 1928. This rule was the basis for the IOC's initial doping regulation, introduced in 1938. Similarly, when the 
IOC tested for banned substances in the late 1960s, the IAAF played a critical role in developing the anti-doping procedures conducted by the IOC. ${ }^{11}$

In more recent times, different IFs' implementation of doping regulations serves as examples of the federations' impact on international sport. For example, the International Skating Union (ISU) and the International Cycling Union (UCI) were heavily involved in the development of the Athlete Biological Passport, installing their own passports before the World Anti-Doping Agency (WADA) released its version in 2009. ${ }^{12}$ The ISU also sanctioned the first athlete, German speed skater Claudia Pechstein, based on her blood values and profile. ${ }^{13}$ The IOC also occasionally grants the IFs authority to make individual decisions for their own sports in regard to Olympic competitions, such as when the IFs decided whether or not Russian athletes could participate in their sports in the 2016 Rio Olympics.

Finally, IFs also wield significant power in resolving disputes. IFs are selforganized and act within a closed network comprised of other sporting bodies. These networks are generally independent from outside control, such as through government regulation or legal jurisdiction, which dissuades external oversight. ${ }^{14}$ IFs' constitutions and charters typically require individuals to resolve disputes internally via sport-specific tribunals, minimizing athletes' and officials' options for conflict resolution. For example, the International Volleyball Federation (FIVB) Constitution mandates resolution in FIVB Judicial Bodies or the Court of Arbitration of Sport, an international body established by the IOC to settle sportrelated conflicts.

Because IFs administer sport on both the national and international levels, their policies significantly affect sport and society. Federations often dictate how, and by whom, sport is played and make wide-ranging decisions that go beyond their own sports. Yet, despite their power and influence, IFs are an underresearched area of sport history. Federation policies shape sport at the local, national, and international levels; therefore, the lack of information about their decisions is a significant research gap, one addressed in this special issue. The papers in this volume highlight institutional sport policies through a sociohistorical lens, demonstrating the ways in which prevailing notions of ability, class, gender, nationalism, and race shaped, and continue to shape, important sport policies.

Although the Olympics increased in importance during the Cold War as a forum to demonstrate national superiority, international politics also infiltrated the IFs. Philippe Vonnard and Sébastien Cala explore the strategies of two major IFsFIFA and the International Skiing Federation (FIS) — in their attempts to resolve the East German question. These two organizations were among the first to accept East Germany as a full member in the early 1950s. However, the decision-making processes differed significantly and whereas the FIS only voted marginally in favor of East Germany's inclusion, FIFA was considerably less divided over the issue. Thus, the paper provides a valuable analysis on how IFs differ in their strategies to combat political challenges.

Kathleen Bachynski studies the remarkable transformation of the sport of ice hockey in North America during the 1960s and 1970s. Across the span of those decades, the sport moved from virtually no players wearing protective headgear to almost every player wearing protective helmets or masks. Bachynski's historical 
account is instructive for understanding decision making in sport organizations more generally, as she demonstrates the complex interplay of actors that gradually reformed the sport: players themselves, coaches and administrators, physicians and other health practitioners, parents, journalists, and many others. Concentrating on policies and practices of the two major amateur hockey associations in the United States and Canada, Bachynski demonstrates that the cultural reproduction of masculine norms and values in the sport interplayed with those organizations' policies to, at first, hold back the movement to include protective headgear, but then later encourage it as those norms and values shifted.

Gender norms also influenced decisions in women's gymnastics, as did concerns about finances and participant well-being. Georgia Cervin explores the history of the International Gymnastics Federation (FIG)'s policies in regard to gender, economics, and athlete welfare. She argues that on all three fronts, the FIG frequently deferred to the IOC to remain a favorite sport in the Olympic Movement. Through the three case studies, Cervin demonstrates the subtle, everpresent power of Olympic officials on the development of women's gymnastics.

Economic forces likewise shaped track and field. The paper by April Henning and Jörg Krieger examines the transition of the IAAF from an amateur sport federation to a professional sport governing body in the 1980s and 1990s. They demonstrate how the IAAF implemented and maintained strict amateur regulations despite an awareness of undercover professionalism in the sport. As the federation created increasing income from staging international events and sponsorships, it turned slowly away from amateur athletics and ushered in a new era of professional athletics. The authors highlight that the final step in this process was the drop of the term "amateur" from the IAAF's original name.

Tom Fabian provides a needed history of volleyball and analyzes its overseeing federation, the FIVB. Invented in 1895 in Massachusetts, United States, volleyball quickly spread around the world. Although volleyball includes the greatest number of participants and oversees a significant number of competitions, the FIVB remains out of both the academic and public spotlight. Researchers and the media alike have ignored the sport, which, according to Fabian, allowed corruption within the FIVB to go unnoticed. By highlighting the governance issues in the volleyball organization, Fabian demonstrates the need for additional critical scholarship on IFs.

Anti-doping policies are among the most important in international sport, and Emmanuel Macedo provides an account of one of the most significant, yet understudied organizations that has produced some of the most impactful policies globally: the Council of Europe. Created in the aftermath of the Second World War, the Council of Europe sought to encourage intercultural exchange and defend human rights in Europe. It took an active interest in the role sport could play in western European countries. Troubled by rumors of elite athletes using performance-enhancing substances, the Council created working parties to study the issue in the early 1960s, before any major sport organization had created their own sanctions. The Council's work in the ensuing decades, Macedo shows, were instrumental in sport organizations' policies at the highest levels, including the IOC and, recently, WADA. The historical context of the Council of Europe's work on the issue, Macedo also demonstrates, is crucial in terms of understanding the subsequent direction of policies that would attempt to police 
athletes' lives in the waning decades of the twentieth century and now into the twenty-first century.

As shown throughout the special issue, IFs are significant power structures in sport; however, they also remain deferential to the IOC, as demonstrated in Callie Maddox's paper. The IOC removed baseball and softball from the Olympic program following the 2008 Beijing Olympics. Maddox explains that when faced with Olympic exclusion, the International Baseball Federation (IBAF) and the International Softball Federation (ISF) merged in 2013, forming the World Baseball Softball Confederation (WBSC). The IBAF and the ISF believed a unified bid from one entity increased the chances for reinstatement, seemingly correct in that both will be played in 2020. Yet, as Maddox writes, both organizations embraced gendered assumptions about who participates in baseball, men, versus who participates in softball, women. She concludes that while the long-term success of the merger is yet to be determined - the IOC has not accepted either sport for the 2024 Olympics - the maneuver did reproduce gender assumptions about baseball and softball.

Collectively, the papers in this special issue illustrate the importance of the IFs in shaping international sport. Although most scholarly accounts focus on the significance of the IOC and the Olympic Games, federations also determine how sport is played, where, and by whom. The special issue addresses this research gap by highlighting the role of IFs in responding to challenging issues in sport.

\section{Notes}

1. For a differentiation of the two terms, see: Mark Dyreson, "The United States of America," in Routledge Companion to Sports History, eds. Steven W. Pope and John R. Nauright (New York: Routledge, 2009), 599-623.

2. Matthew P. Llewellyn and John Gleaves, The Rise and Fall of Olympic Amateurism (Champaign: University of Illinois Press, 2016).

3. Jean-Loup Chappelet and Brenda Kübler-Mabbott, The International Olympic Committee and the Olympic System: The Governance of World Sport (New York: Routledge, 2008), 72-74.

4. Ibid.

5. Alain Ferrand, Jean-Loup Chappelet, and Benoit Séguin, Olympic Marketing (New York: Routledge, 2012), 22.

6. Rob Beamish and Ian Ritchie, Fastest, Highest, Strongest. A Critique of High-Performance Sport (New York and London: Routledge, 2006), 17.

7. Tariq Panja, "FIFA Set to Make \$6.1 Billion from World Cup," The New York Times, June 12, 2018, https://www.nytimes.com/2018/06/12/sports/fifa-revenue.html.

8. Matthew P. Llewellyn and Robert J. Lake, “'The Old Days of Amateurism Are Over': The Samaranch Revolution and the Return of Olympic Tennis," Sport in History 37, no. 4 (2017): 423-447.

9. Robert J. Lake and Matthew P. Llewellyn, "The Demise of Olympic Lawn Tennis in the 1920s: A Case Study of Shifting Relations between the IOC and International Sports Federations," Olympika: The International Journal of Olympic Studies 24, no. 1 (2015): 94-119.

10. Lindsay P. Pieper, Sex Testing: Gender Policing in Women's Sports (Champaign: University of Illinois Press, 2016), 73.

11. Jörg Krieger, Dope Hunters: The Influence of Scientists on the Global Fight against Doping in Sport, 1967-1992 (Champaign, IL: Common Ground, 2015), 125-137. 
12. Thijs Devriendt, Davit Chokoshvili, and Pascal Borry, "The Athlete Biological Passport: Challenges and Possibilities," International Journal of Sport Policy and Politics 11, no. 2 (2019): 315-324.

13. David McArdle, "Longitudial Profiling, Sports Arbitration and the Woman Who Had Nothing to Lose: Some Thoughts on Pechstein v. International Skating Union," in Doping and Anti-Doping Policy in Sport: Ethical, Legal and Social Perspectives, eds. Mike McNamee and Verner Møller (New York: Routledge, 2011), 50-65.

14. Arnout Geeraert, Jeroen Scheerder, and Hans Bruyninckx, "The Governance Network of European Football: Introducing New Governance Approaches to Steer Football at the EU Level," International Journal of Sport Policy and Politics 5, no. 1 (2013): 113-132. 